\title{
The Possible Impact of Aortic Stiffness on Quality of Late Life: An Exploratory Study
}

This article was published in the following Dove Press journal:

Clinical Interventions in Aging

\author{
Lisanne Tap (iD) \\ Lisanne J Dommershuijsen' \\ Andrea Corsonello ${ }^{2}$ \\ Fabrizia Lattanzio ${ }^{2}$ \\ Silvia Bustacchini id ${ }^{2}$ \\ Gijsbertus Ziere (iD) \\ Jan LCM van Saase ${ }^{3}$ \\ Francesco US Mattace-Raso iD \\ 'Section of Geriatric Medicine, \\ Department of Internal Medicine, \\ Erasmus MC, University Medical Center \\ Rotterdam, Rotterdam, the Netherlands; \\ ${ }^{2}$ Italian National Research Center on \\ Aging (INRCA), Ancona, Fermo and \\ Cosenza, Italy; ${ }^{3}$ Department of Internal \\ Medicine, Erasmus MC, University \\ Medical Center Rotterdam, Rotterdam, \\ the Netherlands
}

Correspondence: Francesco US MattaceRaso

Section Geriatric Medicine, Department of Internal Medicine, Erasmus MC, University Medical Center Rotterdam, Room Rg-527, PO BOX 2040, Rotterdam $3000 \mathrm{CA}$, the Netherlands

Tel +3I 107035979

$\mathrm{Fax}+31107034768$

Email f.mattaceraso@erasmusmc.nl
Purpose: Aortic stiffness (AS) is associated with cardiovascular events and all-cause mortality in the older population. AS might also influence the health-related quality of life (HRQOL) as a result of the negative effects of AS on cognitive and physical morbidity. We aimed to investigate the possible association between AS and HRQOL in people aged 75 years and over.

Patients and Methods: This cross-sectional study was part of the SCOPE study, an international multicenter cohort observational study. The indicators for AS were aortic pulse wave velocity (aPWV) and central pulse pressure (cPP). HRQOL was assessed using the EQ-5D index and the EQ-5D visual analog scale (VAS). ANCOVA and multivariate regression models were used to investigate possible associations.

Results: We included 280 Dutch participants of the SCOPE study. Median age was 79 years (IQR 76-83) and 42.1\% were women. Participants reporting any problem on the EQ-5D index $(n=214)$ had higher values of aPWV $(12.6 \mathrm{vs} 12.2 \mathrm{~m} / \mathrm{s}, \mathrm{p}=0.024)$ than participants not experiencing any problem $(n=66)$ and comparable values of cPP $(44.4$ vs $42.0 \mathrm{mmHg}, \mathrm{p}=$ 0.119 ). Estimates only slightly changed after adjustments. No association was found between indicators of AS and EQ-5D VAS.

Conclusion: Aortic stiffness was associated with impaired quality of late life. This association could be mediated by subclinical vascular pathology affecting mental and physical health.

Keywords: arterial stiffness, health-related quality of life, EQ-5D, older persons

\section{Introduction}

Aortic stiffness is a part of vascular aging, ${ }^{1-3}$ a phenomenon which can be accelerated by risk factors such as hypertension and diabetes mellitus. ${ }^{4-9}$ Aortic stiffness is a powerful predictor of cardiovascular events and all-cause mortality in several clinical populations as well as in community-dwelling older people. ${ }^{10-12}$ Aortic stiffness is also associated with microvascular brain disease, ${ }^{13,14}$ which can lead to decreased mental health in terms of cognition, mood, and daily functioning. ${ }^{15,16}$ As a result of these effects, aortic stiffness might also have a negative impact on quality of life. The negative impact of aortic stiffness on quality of life could be a subclinical result of vascular pathology or a result of the presence of comorbidities. ${ }^{17-20}$

Previous studies have investigated the possible association between aortic stiffness and quality of life in several study populations. ${ }^{21-27}$ These studies show conflicting results. Moreover, to the best of our knowledge, no previous study has investigated the possible association between aortic stiffness and the quality of late life. 
Studying quality of life is relevant, since quality of life is a more powerful predictor of morbidity and mortality than many objective measures of health. ${ }^{28}$ Health-related quality of life (HRQOL) can be seen as a broad measure of health status and a supplement to traditional parameters as morbidity and mortality.

The objective of this study was to determine whether there is an association between aortic stiffness and quality of life in older persons aged 75 years and over.

\section{Materials and Methods Study Population}

The Screening for Chronic kidney disease among Older People across Europe (SCOPE) study is a multicenter observational study with a prospective design in seven European countries. ${ }^{29}$ The primary objective of the study is to investigate the currently available screening methods to identify community-dwelling older patients at risk of kidney disease. A detailed description of the study protocol can be found elsewhere. ${ }^{29}$ Patients with end-stage renal disease or dialysis, a history of solid organ or bone marrow transplantation, an active malignancy or metastatic cancer within 24 months prior to the visit, a life expectancy of less than 6 months, a severe cognitive impairment or patients unwilling to provide consent were ineligible for the SCOPE study. The current study population was a subset of the SCOPE study population including only the Dutch participants $(n=301)$. Data on aortic stiffness were only collected at participating centers in the Netherlands. The SCOPE study has been reviewed and approved by the Medical Ethics Committee of the Erasmus MC University Medical Center. This trial was conducted in accordance with the Declaration of Helsinki. This study was registered on the 25th February 2016 at clinicaltrials.gov, identifier NCT02691546. All participants provided written informed consent.

\section{Study Visit}

Baseline visit was scheduled at the Erasmus Medical Center Rotterdam or at the Havenziekenhuis Rotterdam. A comprehensive geriatric assessment was performed according to the SCOPE study protocol. ${ }^{29}$ The assessment included questionnaires, physical examination, and functional tests. Also, non-fastened blood and urine samples were taken.

\section{Aortic Stiffness}

Aortic stiffness was determined measuring aortic Pulse Wave Velocity (aPWV) with the Mobil-O-Graph (IEM,
Rheinland, Germany), a previously validated oscillometric method. ${ }^{30}$ aPWV measurements were performed by a single measurement in resting sitting position using a brachial cuff. Other hemodynamic parameters that were obtained during the same measurement using inbuilt algorithms included blood pressure (both peripheral and central), mean arterial pressure (MAP), and heart rate (HR). In addition to aPWV, central pulse pressure (cPP) was also used as indicator of aortic stiffness. ${ }^{31,32} \mathrm{cPP}$ was defined as the difference between central systolic blood pressure (SBP) and central diastolic blood pressure (DBP). The measurement was carried out in every participant. However, we excluded participants in which the device was not able to conduct a proper wave analysis due to technical issues.

\section{Health-Related Quality of Life}

The Euro QoL-5-dimensions (EQ-5D) questionnaire was used to measure HRQOL. ${ }^{33}$ The 5-level EQ-5D questionnaire has been validated in a variety of patient groups in six different countries, including the Netherlands. ${ }^{34}$ The questionnaire consists of two parts: a descriptive profile and a visual analogue scale (VAS). The descriptive part of the questionnaire provides information on the following five dimensions: mobility, self-care, daily activities, pain and discomfort, and anxiety and depression. A five-level Likert scale from no problems to being unable to function on the specific domain was used to gather information about the specific domains. This information was then converted into a single index value that informs on the overall HRQOL. ${ }^{35}$ To calculate the EQ-5D index, a formula is used that weighs each dimension value with a tariff specific for the country at stake. The Dutch tariff was used in this study. ${ }^{36}$ The index value is depicted on a scale with 0 indicating death and 1 indicating full health. The EQ-5D VAS is a $20 \mathrm{~cm}$ scale from 0 to 100 in which respondents can fill out their current state of health. Zero equals the worst imaginable health status and 100 the best imaginable health status.

\section{Statistical Analysis}

Statistical analyses were performed using IBM SPSS Statistics version 24 for Windows. Participants with missing values for the aortic stiffness parameters were excluded. Descriptive statistics were expressed as percentage for categorical variables, mean and standard deviation $( \pm \mathrm{SD})$ for continuous normally distributed variables, and median and interquartile ranges [IQR] for continuous non-normally distributed variables. Participants with an EQ-5D index value of 1 were classified as "no problem on any dimension" 
(group 1), participants with an EQ-5D index value lower than 1 were classified as "any problem on the five dimensions" (group 2). First, characteristics were compared between these groups using the Mann-Whitney $U$-test and $t$-test for continuous variables. The Chi-square test was used to compare percentages. An analysis of covariance (ANCOVA) was used to investigate the possible association between aortic stiffness and the dichotomized version of EQ-5D index. Mean levels of aPWV and cPP were compared between these groups using two different models. Mean levels of pDBP and cDBP were also compared between these groups. We have identified potential covariates and included covariates with a $\mathrm{p}$-value $<0.1$ in the adjusted models when appropriate. Model 1 was adjusted for age, sex, mean arterial pressure and heart rate. Model 2 was additionally adjusted for Cumulative Illness Rating Scale (total score). A multivariable linear regression model was built to investigate the possible association between aortic stiffness (aPWV and cPP) and the EQ-5D VAS using the same models. A p-value of $<0.05$ was considered statistically significant.

\section{Results}

In total, 280 of the 301 Dutch participants were included in the study, 21 participants were not included due to missing values of aortic stiffness. Characteristics are shown in Table 1. Median age was 79 years [IQR 76-83] and $42.1 \%$ were women. Few participants were ADL dependent $(15.4 \%)$ and $48.6 \%$ of the participants were iADL dependent. Over $70 \%$ of the 280 participants had hypertension, $26.4 \%$ diabetes mellitus, $23.6 \%$ a history of malignancy, $21.1 \%$ COPD, $20.4 \%$ a history of stroke and $17.1 \%$ atrial fibrillation. The mean score on the cumulative illness rating scale (CIRS) was $12.8 \pm 4.9$ and the mean severity index of the CIRS was $1.8 \pm 0.3$. The maximum value of 1 on the EQ5D index (no problems) was scored by 66 participants (23.6\%). Participants reporting any problem on the EQ-5D index $(76.4 \%)$ were older, more often women, more often iADL dependent, had higher scores on the geriatric depression scale and also higher comorbidity rates than those without problems on the EQ-5D index, which resulted in a higher CIRS total score (mean values $13.4 \pm 4.9$ vs 10.9 $\pm 4.4, \mathrm{p}<0.001)$. Characteristics stratified for problems on the EQ-5D index are also presented in Table 1.

Participants with any problem on the EQ-5D index had lower peripheral (pDBP) and central DBP (cDBP) than participants without problems on the EQ-5D index. Mean values were $84.1 \pm 10.9$ vs $88.4 \pm 11.8 \mathrm{mmHg}(\mathrm{p}=0.006)$ and
$85.7 \pm 11.0$ vs $90.3 \pm 11.8 \mathrm{mmHg}(\mathrm{p}=0.004)$, respectively. Also, participants with any problem on the EQ-5D index had higher values of aPWV than participants without problems on the EQ-5D index $(\mathrm{p}=0.024)$. Mean values were $12.6 \pm 1.3$ and $12.2 \pm 0.9 \mathrm{~m} / \mathrm{s}$, respectively.

Table 2 shows the characteristics of the EQ-5D outcome measures. Median EQ-5D index was 0.86 [IQR 0.81-0.91] and the mean EQ-5D VAS was 74.9 \pm 14.8 . No problems were reported by $42.5 \%$ of participants on mobility, $92.5 \%$ on self-care, $78.9 \%$ on daily activities, $44.6 \%$ on pain and discomfort, and $83.6 \%$ on anxiety and depression.

Figure 1 shows the mean levels of aortic stiffness according to EQ-5D index status (no problem vs any problem). The mean values of aPWV were higher in the any problem group than in the no problem group $(12.52 \mathrm{~m} / \mathrm{s}$ vs $12.39 \mathrm{~m} / \mathrm{s}, \mathrm{p}=0.024)$. In model 2, the mean aPWV values remained unchanged with a $0.12 \mathrm{~m} / \mathrm{s}$ higher mean aPWV in the group with any problem $(p=0.041)$. The mean values of cPP were $3.3 \mathrm{mmHg}$ higher in the any problem group than in the no problem group (44.6 $\mathrm{mmHg}$ vs $41.3 \mathrm{mmHg}, \mathrm{p}=0.042$ ). This difference persisted in model 2 (44.6 mm Hg vs $41.2 \mathrm{mmHg}, \mathrm{p}=0.041$ ).

Mean levels of pDBP and cDBP were also compared between the two groups (no problem vs any problem). However, in multivariate analysis in both model 1 and model 2, mean values did not differ between groups (data not shown). A trend was observed between aPWV and EQ5D VAS in model 1 . Per $\mathrm{m} / \mathrm{s}$ increase in aPWV, the EQ-5D VAS score changed with -4.15 (95\% CI -8.71-0.42), whereas no association was found in model 2. No association was found between cPP and the EQ-5D VAS. In model 1, B coefficient and 95\% CI for cPP were $-0.05(-0.21-$ $0.11)$; Estimates in model 2 were only slightly changed.

\section{Discussion}

In this exploratory study, we found that aortic stiffness, assessed as aortic pulse wave velocity and central pulse pressure, was associated with an impaired quality of life in people of 75 years and over. This association in late life was independent of age, blood pressure levels, and comorbidities.

Several mechanisms might explain our results. First, the association between aortic stiffness and quality of late life could be mediated by impaired physical health. Aortic stiffness is known to play an important role in the development and progression of diseases in end-organs and the presence of these diseases could affect the quality of life. ${ }^{37}$ However, the association between aortic stiffness and quality of life persisted even after adjustment for cumulative comorbidities suggesting an independent role of aortic stiffness. Second, 
Table I Participants' Characteristics $(n=280)$

\begin{tabular}{|c|c|c|c|c|}
\hline Characteristics & Total & $\begin{array}{l}\text { No Problem EQ-5D } \\
\text { Index }(n=66)\end{array}$ & $\begin{array}{l}\text { Any Problem EQ-5D } \\
\text { Index }(n=2 \mid 4)\end{array}$ & p-value \\
\hline Age, years & 79 [76-83] & $78[76-81]$ & 79 [76-84] & 0.047 \\
\hline Women, \% & 42.1 & 28.8 & 46.3 & 0.012 \\
\hline Education, years & $12.1( \pm 4.5)$ & $12.7( \pm 4.9)$ & $11.9( \pm 4.4)$ & 0.179 \\
\hline Packyears of smoking, years & $5[0-20]$ & $3.9[0-20]$ & $6[0-20.4]$ & 0.528 \\
\hline Current smoker, \% & 5.0 & 3.0 & 5.6 & 0.824 \\
\hline Alcohol consumption $\geq 1$ unit a day, $\%$ & 34.3 & 39.4 & 32.7 & 0.317 \\
\hline BMI, kg/m² & $26.3( \pm 4.3)$ & $26.1( \pm 3.3)$ & $26.3( \pm 4.5)$ & 0.760 \\
\hline ADL dependent, \% & 15.4 & 9.1 & 17.3 & 0.106 \\
\hline iADL dependent, \% & 48.6 & 25.8 & 55.6 & $<0.001$ \\
\hline MMSE, score & $29[27-30]$ & $28[27-30]$ & $29[27-30]$ & 0.988 \\
\hline GDS, score & $2[1-3]$ & $0[0-1]$ & $2[1-4]$ & $<0.001$ \\
\hline eGFR-BIS, $\mathrm{mL} / \mathrm{min}$ & $47.2( \pm 13.6)$ & $46.6( \pm 13.1)$ & $47.3( \pm 13.8)$ & 0.701 \\
\hline Hypertension, \% & 70.7 & 62.1 & 73.4 & 0.079 \\
\hline Diabetes Mellitus, \% & 26.4 & 27.3 & 26.2 & 0.859 \\
\hline History of TIA/CVA, \% & 20.4 & 15.2 & 22.0 & 0.230 \\
\hline Atrial fibrillation, \% & 17.1 & 10.6 & 19.2 & 0.107 \\
\hline COPD, \% & 21.1 & 10.6 & 24.3 & 0.017 \\
\hline History of malignancy, \% & 23.6 & 15.2 & 26.2 & 0.065 \\
\hline CIRS, total score & $12.8( \pm 4.9)$ & $10.9( \pm 4.4)$ & $13.4( \pm 4.9)$ & $<0.001$ \\
\hline CIRS, severity index & $1.8( \pm 0.3)$ & I.8 $( \pm 0.3)$ & $1.9( \pm 0.3)$ & 0.271 \\
\hline \multicolumn{5}{|l|}{ Vascular Parameters } \\
\hline pSBP, $\mathrm{mmHg}$ & $|46|.( \pm 20.2)$ & $148.2( \pm 20.3)$ & $145.4( \pm 20.1)$ & 0.337 \\
\hline $\mathrm{pDBP}, \mathrm{mmHg}$ & $85.1( \pm \mid 1.2)$ & $88.4( \pm \mid 1.8)$ & $84.1( \pm 10.9)$ & 0.006 \\
\hline MAP, $\mathrm{mmHg}$ & $113.0( \pm 14.0)$ & $115.8( \pm 14.8)$ & $112.2( \pm 13.6)$ & 0.068 \\
\hline $\mathrm{pPP}, \mathrm{mmHg}$ & $60.9( \pm 15.5)$ & $59.7( \pm \mid 3.8)$ & $61.2( \pm 16.0)$ & 0.509 \\
\hline Heart rate, bpm & $69.8( \pm 12.2)$ & $70.5( \pm 12.9)$ & $69.5( \pm 11.9)$ & 0.579 \\
\hline $\mathrm{cSBP}, \mathrm{mmHg}$ & $130.6( \pm \mid 7.4)$ & $132.2( \pm 16.6)$ & $130.1( \pm \mid 7.6)$ & 0.395 \\
\hline cDBP, $\mathrm{mmHg}$ & $86.7( \pm 11.3)$ & $90.3( \pm 11.8)$ & $85.7( \pm 11.0)$ & 0.004 \\
\hline $\mathrm{cPP}, \mathrm{mmHg}$ & $43.8( \pm 12.8)$ & $42.0( \pm 10.1)$ & $44.4( \pm 13.5)$ & 0.119 \\
\hline aPWV, $\mathrm{m} / \mathrm{s}$ & $12.5( \pm \mid .2)$ & $12.2( \pm 0.9)$ & $12.6( \pm \mid .3)$ & 0.024 \\
\hline
\end{tabular}

Notes: Continuous variables are presented as mean $( \pm \mathrm{SD})$ or median $[\mathrm{IQR}]$. P-values are based on T-test and Mann-Whitney U-Test for continuous variables and Chi-square test for categorical variables. P-values in bold indicate significant differences $(P<0.05)$ between groups.

Abbreviations: BMI, Body Mass Index; (i)ADL, (instrumental) Activities of Daily Living; MMSE, Mini-Mental State Examination; GDS, Geriatric Depression Scale; eGFR-BIS, estimated Glomerular Filtration Rate; TIA/CVA, transient ischemic attack/cerebrovascular accident; COPD, chronic obstructive pulmonary disease; CIRS, Cumulative Illness Rating Scale; pSBP, peripheral systolic blood pressure; pDBP, peripheral diastolic blood pressure; MAP, mean arterial pressure; pPP, peripheral pulse pressure; cSBP, central systolic blood pressure; cDBP, central diastolic blood pressure; aPWV, aortic Pulse Wave Velocity; cPP, central Pulse Pressure.

impaired mental health could also mediate the association between aortic stiffness and quality of life. Elevated aortic stiffness can lead to cerebral small vessel disease, which is associated with cognitive decline as well as mood disturbances. ${ }^{15,38-40}$ It is very well possible that quality of life questionnaires might be able to detect vascular pathology already in a subclinical stage. Subclinical vascular damage could be already revealed in measures of quality of life before it results in multiple physical and mental comorbidities. An increase in aPWV of $1 \mathrm{~m} / \mathrm{s}$ amplifies the risk of cardiovascular morbidity and mortality as well as all-cause mortality by $15 \% .{ }^{10}$ In this study, we found $0.12 \mathrm{~m} / \mathrm{s}$ higher
aPWV and $3.4 \mathrm{mmHg}$ higher cPP in participants with poorer quality of life indexes. Although an increase in aPWV of $0.12 \mathrm{~m} / \mathrm{s}$ or $3.4 \mathrm{mmHg}$ higher $\mathrm{cPP}$ may seem relatively modest and the effect size is small, these differences could already have an impact on daily functioning, both physically and mentally. Therefore, aortic stiffness might be a tissue biomarker reflecting the vitality status of the single individual. In addition, aortic stiffness determines high mean SBP levels and low DBP levels, and consequently a wide pulse pressure. $^{41}$ It can be speculated that aortic stiffness together with consequent aberrant hemodynamic changes can affect quality of life by determining cardiovascular morbidity. It 
Table 2 Characteristics of Health-Related Quality of Life $(n=280)$

\begin{tabular}{|l|l|}
\hline Characteristics & \\
\hline EQ-5D index, score & $0.86[0.8 \mathrm{I}-0.9 \mathrm{I}]$ \\
EQ-5D VAS, score & $74.9( \pm \mid 4.8)$ \\
\hline No Problems per Dimension & \\
Mobility, \% & 42.5 \\
Self-care, \% & 92.5 \\
Daily activities, \% & 78.9 \\
Pain/discomfort, \% & 44.6 \\
Anxiety/depression, \% & 83.6 \\
\hline
\end{tabular}

Note: Continuous variables are presented as mean ( $\pm S D$ ) or median [IQR].

Abbreviation: EQ-5D VAS, EQ-5D Visual Analogue Scale.

cannot be excluded that lower quality of life may also have an effect on aortic stiffness. It has been suggested that lower quality of life also represents people with lower social support or more depressive symptoms. ${ }^{42,43}$ As result of this, it could be hypothesized that lower quality of life might also affect (hypertension) treatment compliance and therefore deterioration of health which negatively affects the function of the arteries. In addition, lower mobility and the presence of depressive symptoms and pain may also perpetuate a physically inactive lifestyle, which is associated with a change in vascular function and increase in stiffness. ${ }^{44}$

We found a discrepancy in the results of the EQ-5D index and the EQ-VAS. This discrepancy could be explained by the nature of the questionnaires. Noticing and reporting actual disabilities in daily life in the EQ5D index does not necessarily mean that the selfperceived health on the EQ-VAS is scored as worse. Namely since in the EQ-VAS, an individual values his or her health position in life in the context of cultural

\section{Model 1}

A

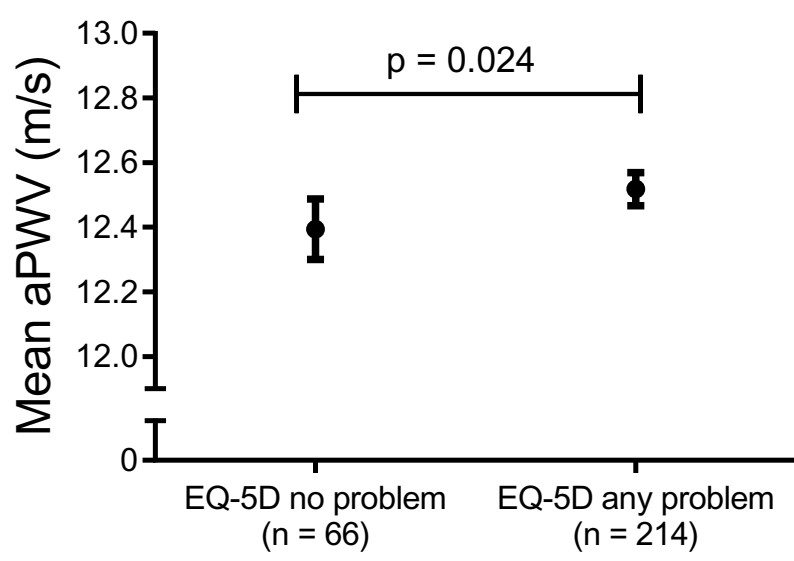

C

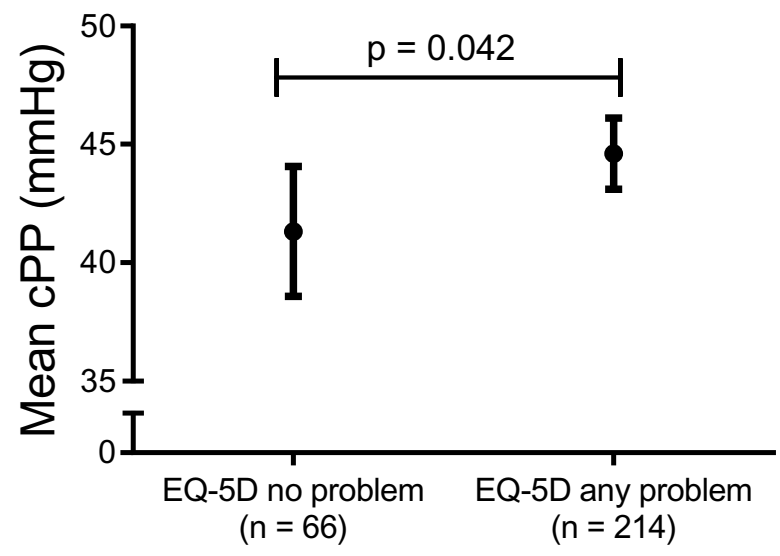

Model 2

B

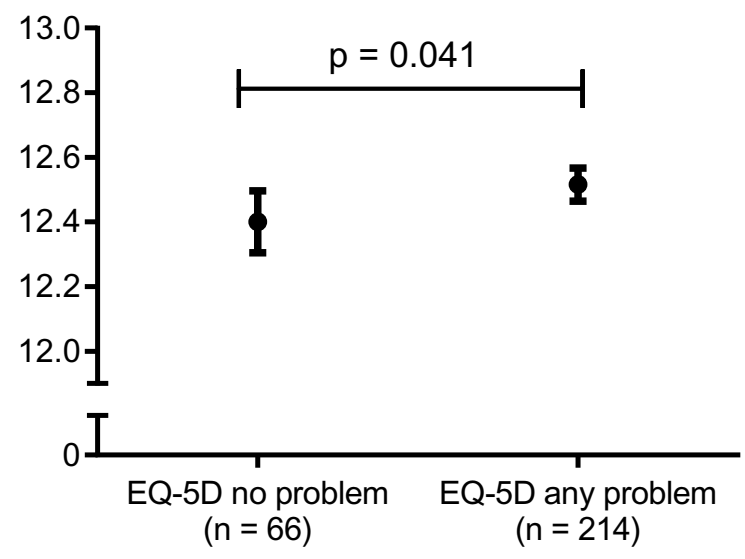

D

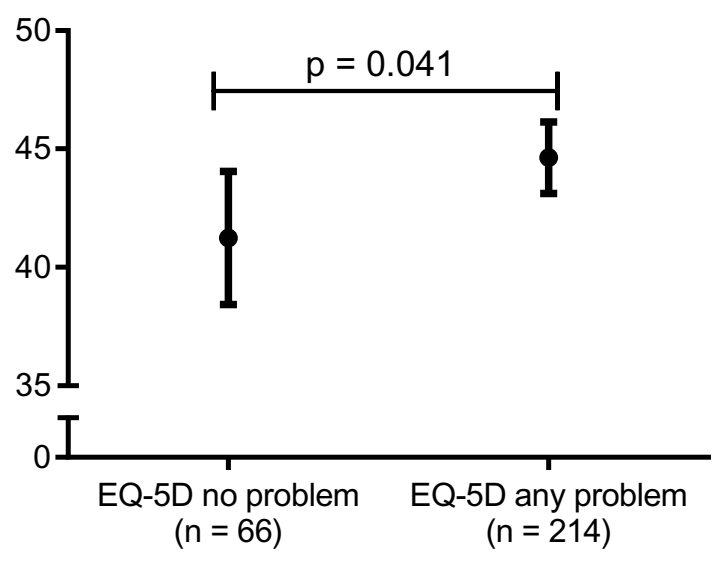

Figure I Mean values of aortic stiffness according to EQ-5D index status $(n=280)$.

Notes: (A and B): aortic Pulse Wave Velocity (aPWV) in m/s; (C and $\mathbf{D})$ : central Pulse Pressure (cPP) in mmHg. Model I: adjusted for age, sex, mean arterial pressure and heart rate; Model 2: additionally adjusted for Cumulative Illness Rating Scale total score. Dots represent mean values, bars represent $95 \%$ confidence intervals. 
and social aspects. In other words, these two questionnaires score different aspects of quality of life. Another well-known problem with the EQ-VAS is the end-ofscale bias which results in small numbers of extreme values, which could make the EQ-VAS less reliable than the EQ-5D index.

Some aspects of this study need further consideration. First, the cross-sectional study design does not allow to draw causal inferences. Second, the sample size was relatively small and the population consisted of outpatient older persons. This could affect the power to investigate possible associations between aortic stiffness and quality of life. However, despite the limited number of participants and the possible selection bias, we were able to detect significant differences with a small effect size between those with and without problems in quality of life. The difference in cPP reached statistical significance in adjusted models, which might suggest that this result is due to chance or that the sample size for this specific analysis is underpowered. In a larger and more heterogeneous population, these differences might be amplified. Third, we measured aortic stiffness with an oscillometric method. This method is validated and gives reliable results when compared to invasive measurements, ${ }^{30}$ however, the predictive value of this measurement to cardiovascular outcomes has not been investigated. One of the strengths of this study is the fact that we categorized EQ5D index into no problem and any problem. The splitting partly resolved the problem of skewed values, but this made the results also more relevant in clinical practice. Another strength is the use of several markers of aortic stiffness such as aPWV and cPP. These central measures play a fundamental role in end organ disease and are therefore accurate and clinically relevant markers. ${ }^{32,37}$

The association between aortic stiffness and quality of life has been investigated before. Nevertheless, most previous studies did not observe an effect on overall HRQOL but only on the physical component of the HRQOL. ${ }^{21,23,24,27}$ Only one study has described an effect on overall HRQOL. ${ }^{25}$ However, this study was performed in a very small sample of 56 patients undergoing surgical aortic valve replacement. Our study sample differed from previous studies, since we have focussed on a specific population of older patients in late life, whereas the previous studies have focussed on younger patients or specific patient categories.

\section{Conclusion}

In conclusion, aortic stiffness was associated with impaired quality of life in people of 75 years and over. This association in late life was independent of age and other cardiovascular risk factors and might be mediated by subclinical vascular pathology affecting mental and physical health. Future research is required to establish whether aortic stiffness has a predictive value for a deterioration in quality of life.

\section{Acknowledgments}

The authors thank all the investigators of the SCOPE consortium for the collaboration within the SCOPE project. The authors would like to thank Anneke Snel, medical student at the Erasmus MC, University Medical Center Rotterdam, for her input within the data processing. The authors would also like to thank Wave Medical BV Heerenveen, the Netherlands, for logistic support for performing this study (Mobil-o-graph device).

\section{Disclosure}

Part of this work was supported by the European Union Horizon 2020 program [grant number 634869]. The authors report no other conflicts of interest in this work.

\section{References}

1. Lakatta EG, Levy D. Arterial and cardiac aging: major shareholders in cardiovascular disease enterprises: part I: aging arteries: a "set up" for vascular disease. Circulation. 2003;107(1):139-146. doi:10.1161/01. CIR.0000048892.83521.58

2. Ghebre YT, Yakubov E, Wong WT, et al. Vascular aging: implications for cardiovascular disease and therapy. Transl Med (Sunnyvale). 2016;6(4). doi:10.4172/2161-1025.1000183

3. McEniery CM, Yasmin HIR, Qasem A, et al. Normal vascular aging: differential effects on wave reflection and aortic pulse wave velocity: the Anglo-Cardiff Collaborative Trial (ACCT). J Am Coll Cardiol. 2005;46(9):1753-1760. doi:10.1016/j.jacc.2005.07.037

4. van Popele NM, Elizabeth Hak A, Mattace-Raso FU, et al. Impaired fasting glucose is associated with increased arterial stiffness in elderly people without diabetes mellitus: the Rotterdam Study. J Am Geriatr Soc. 2006;54(3):397-404. doi:10.1111/j.1532-5415.2005.00614.x

5. Riley WA, Freedman DS, Higgs NA, Barnes RW, Zinkgraf SA, Berenson GS. Decreased arterial elasticity associated with cardiovascular disease risk factors in the young. Bogalusa Heart Study. Arteriosclerosis. 1986;6(4):378-386. doi:10.1161/01.ATV.6.4.378

6. Simon AC, Levenson J, Bouthier J, Safar ME, Avolio AP. Evidence of early degenerative changes in large arteries in human essential hypertension. Hypertension. 1985;7(5):675-680. doi:10.1161/01.HYP.7.5.675

7. Smulyan H, Lieber A, Safar ME. Hypertension, diabetes type II, and their association: role of arterial stiffness. Am J Hypertens. 2016;29 (1):5-13. doi:10.1093/ajh/hpv107

8. Prenner SB, Chirinos JA. Arterial stiffness in diabetes mellitus. Atherosclerosis. 2015;238(2):370-379. doi:10.1016/j.atherosclerosi s.2014.12.023

9. Verwoert GC, Franco OH, Hoeks AP, et al. Arterial stiffness and hypertension in a large population of untreated individuals: the Rotterdam Study. J Hypertens. 2014;32(8):1606-1612. doi:10.1097/ HJH.0000000000000237 
10. Vlachopoulos C, Aznaouridis K, Stefanadis C. Prediction of cardiovascular events and all-cause mortality with arterial stiffness: a systematic review and meta-analysis. J Am Coll Cardiol. 2010;55 (13):1318-1327. doi:10.1016/j.jacc.2009.10.061

11. Ben-Shlomo Y, Spears M, Boustred C, et al. Aortic pulse wave velocity improves cardiovascular event prediction: an individual participant meta-analysis of prospective observational data from 17,635 subjects. J Am Coll Cardiol. 2014;63(7):636-646. doi:10.1016/j. jacc.2013.09.063

12. Mattace-Raso FU, van der Cammen TJ, Hofman A, et al. Arterial stiffness and risk of coronary heart disease and stroke: the Rotterdam Study. Circulation. 2006;113(5):657-663. doi:10.1161/CIRCULATIONAHA. 105.555235

13. Tap L, van Opbroek A, Niessen WJ, Smits M, Mattace-Raso FU. Aortic stiffness and brain integrity in elderly patients with cognitive and functional complaints. Clin Interv Aging. 2018;13:2161-2167. doi: $10.2147 / \mathrm{CIA}$

14. Poels MM, Zaccai K, Verwoert GC, et al. Arterial stiffness and cerebral small vessel disease: the Rotterdam Scan Study. Stroke. 2012;43(10):2637-2642. doi:10.1161/STROKEAHA.111.642264

15. van Sloten TT, Protogerou AD, Henry RM, Schram MT, Launer LJ, Stehouwer CD. Association between arterial stiffness, cerebral small vessel disease and cognitive impairment: a systematic review and meta-analysis. Neurosci Biobehav Rev. 2015;53:121-130. doi:10.10 16/j.neubiorev.2015.03.011

16. Onete V, Henry RM, Sep SJS, et al. Arterial stiffness is associated with depression in middle-aged men - the Maastricht Study. J Psychiatry Neurosci. 2017;42(6):160246.

17. Huang ES, Brown SE, Ewigman BG, Foley EC, Meltzer DO. Patient perceptions of quality of life with diabetes-related complications and treatments. Diabetes Care. 2007;30(10):2478-2483. doi:10.2337/dc070499

18. Valderrabano F, Jofre R, Lopez-Gomez JM. Quality of life in end-stage renal disease patients. Am J Kidney Dis. 2001;38 (3):443-464. doi:10.1053/ajkd.2001.26824

19. Mittal SK, Ahern L, Flaster E, Maesaka JK, Fishbane S. Self-assessed physical and mental function of haemodialysis patients. Nephrol Dial Transplant. 2001;16(7):1387-1394. doi:10.1093/ndt/16.7.1387

20. Taylor WD, Aizenstein HJ, Alexopoulos GS. The vascular depression hypothesis: mechanisms linking vascular disease with depression. Mol Psychiatry. 2013;18(9):963-974.

21. Garcia-Ortiz L, Recio-Rodriguez JI, Mora-Simon S, et al. Vascular structure and function and their relationship with health-related quality of life in the MARK study. BMC Cardiovasc Disord. 2016;16:95. doi:10.1186/s12872-016-0272-9

22. Crilly MA, Clark HJ, Kumar V, Scott NW, MacDonald AG, Williams DJ. Relationship between arterial stiffness and Stanford Health Assessment Questionnaire disability in rheumatoid arthritis patients without overt arterial disease. J Rheumatol. 2010;37 (5):946-952. doi:10.3899/jrheum.091052

23. Al Mheid I, Veledar E, Martin GS, Vaccarino V, Quyyumi AA. Functional health and well-being, arterial stiffness and vascular dysfunction in healthy adults. Int $J$ Cardiol. 2014;174(3):729-730. doi:10.1016/j.ijcard.2014.04.024

24. Brunner EJ, Shipley MJ, Witte DR, et al. Arterial stiffness, physical function, and functional limitation: the Whitehall II Study. Hypertension. 2011;57(5):1003-1009. doi:10.1161/HYPERTENSIONAHA.110.168 864

25. Kidher E, Harling L, Nihoyannopoulos P, et al. High aortic pulse wave velocity is associated with poor quality of life in surgical aortic valve stenosis patients. Interact Cardiovasc Thorac Surg. 2014;19 (2):189-197. doi:10.1093/icvts/ivu156

26. Mitu O, Roca M, Leon -M-M, Gherasim A, Graur M, Mitu F. Association of health-related quality of life with cardiovascular risk factors and subclinical atherosclerosis in non-diabetic asymptomatic adults. Biomed Res. 2016;27(3):687-694.
27. Wright L, Gilroy D, Stowasser M, Sharman JE. Aortic stiffness, but not central or brachial blood pressures, predict physical quality of life. Hypertension. 2010;55(6):1492-1513.

28. Idler EL, Benyamini Y. Self-rated health and mortality: a review of twenty-seven community studies. J Health Soc Behav. 1997;38 (1):21-37. doi: $10.2307 / 2955359$

29. Corsonello A, Tap L, Roller-Wirnsberger R, et al. Design and methodology of the screening for CKD among older patients across Europe (SCOPE) study: a multicenter cohort observational study. BMC Nephrol. 2018;19(1):260. doi:10.1186/s12882-0181030-2

30. Hametner B, Wassertheurer S, Kropf J, Mayer C, Eber B, Weber T. Oscillometric estimation of aortic pulse wave velocity: comparison with intra-aortic catheter measurements. Blood Press Monit. 2013;18 (3):173-176. doi:10.1097/MBP.0b013e3283614168

31. Safar ME, Levy BI, Struijker-Boudier H. Current perspectives on arterial stiffness and pulse pressure in hypertension and cardiovascular diseases. Circulation. 2003;107(22):2864-2869. doi:10.1161/01. CIR.0000069826.36125.B4

32. Roman MJ, Devereux RB, Kizer JR, et al. Central pressure more strongly relates to vascular disease and outcome than does brachial pressure: the Strong Heart Study. Hypertension. 2007;50(1):197-203. doi:10.1161/HYPERTENSIONAHA.107.089078

33. Rabin R, de Charro F. EQ-5D: a measure of health status from the EuroQol Group. Ann Med. 2001;33(5):337-343. doi:10.3109/ 07853890109002087

34. Janssen MF, Pickard AS, Golicki D, et al. Measurement properties of the EQ-5D-5L compared to the EQ-5D-3L across eight patient groups: a multi-country study. Qual Life Res. 2013;22(7):171 7-1727. doi:10.1007/s11136-012-0322-4

35. Szende A, Janssen MB, Cabasés JM, Ramos Goñi JM. Self-Reported Population Health: An International Perspective Based on EQ-5D. SpringerOpen; 2014.

36. Versteegh MM, Vermeulen KM, Evers SMAA, de Wit GA, Prenger R, Stolk EA. Dutch tariff for the five-level version of EQ-5D. Value Health. 2016;19(4):343-352. doi:10.1016/j.jval.2016.01.003

37. Humphrey JD, Harrison DG, Figueroa CA, Lacolley P, Laurent S. Central artery stiffness in hypertension and aging: a problem with cause and consequence. Circ Res. 2016;118(3):379-381. doi:10.1161/ CIRCRESAHA.115.307722

38. Cooper LL, Woodard T, Sigurdsson S, et al. Cerebrovascular damage mediates relations between aortic stiffness and memory. Hypertension. 2016;67(1):176-182. doi:10.1161/HYPERTENSIONAHA.115.06398

39. Hajjar I, Goldstein FC, Martin GS, Quyyumi AA. Roles of arterial stiffness and blood pressure in hypertension-associated cognitive decline in healthy adults. Hypertension. 2016;67(1):171-175. doi:10.1161/HYPERTENSIONAHA.115.06277

40. Tiemeier H, Breteler MM, van Popele NM, Hofman A, Witteman JC. Late-life depression is associated with arterial stiffness: a population-based study. J Am Geriatr Soc. 2003;51(8):1105-1110. doi:10.1046/j.1532-5415.2003.51359.x

41. Coutinho T, Bailey KR, Turner ST, Kullo IJ. Arterial stiffness is associated with increase in blood pressure over time in treated hypertensives. J Am Soc Hypertens. 2014;8(6):414-421. doi:10.101 6/j.jash.2014.03.330

42. Gallicchio L, Hoffman SC, Helzlsouer KJ. The relationship between gender, social support, and health-related quality of life in a community-based study in Washington County, Maryland. Qual Life Res. 2007;16(5):777-786. doi:10.1007/s11136-0069162-4

43. Sivertsen H, Bjorklof GH, Engedal K, Selbaek G, Helvik AS. Depression and quality of life in older persons: a review. Dement Geriatr Cogn Disord. 2015;40(5-6):311-339. doi:10.1159/000437299

44. Nosova EV, Yen P, Chong KC, et al. Short-term physical inactivity impairs vascular function. J Surg Res. 2014;190(2):672-682. doi:10. 1016/j.jss.2014.02.001 


\section{Publish your work in this journal}

Clinical Interventions in Aging is an international, peer-reviewed journal focusing on evidence-based reports on the value or lack thereof of treatments intended to prevent or delay the onset of maladaptive correlates of aging in human beings. This journal is indexed on PubMed Central, MedLine, CAS, Scopus and the Elsevier
Bibliographic databases. The manuscript management system is completely online and includes a very quick and fair peer-review system, which is all easy to use. Visit http://www.dovepress.com/ testimonials.php to read real quotes from published authors.

Submit your manuscript here: https://www.dovepress.com/clinical-interventions-in-aging-journal 